\title{
Tumor- and stromal cell-specific expression of topoisomerase II $\alpha$ and HER-2/neu in primary and recurrent ovarian cancer: Results of a prospective study
}

\author{
RADOSLAV CHEKEROV ${ }^{1 *}$, DOMINIQUE KOENSGEN ${ }^{2 *}$, IRINA KLAMAN $^{3}$, ANDRÉ ROSENTHAL $^{3}$, \\ GUELTEN OSKAY-OEZCELIK ${ }^{1}$, ALEXANDER MUSTEA ${ }^{2}$, WERNER LICHTENEGGER ${ }^{1}$, \\ EDGAR DAHL $^{4}$ and JALID SEHOULI ${ }^{1}$
}

\author{
${ }^{1}$ Department of Obstetrics and Gynecology, Campus Virchow Clinic, Charité University Hospital, D-13353 Berlin; \\ ${ }^{2}$ Department of Obstetrics and Gynecology, Ernst Moritz Arndt University, D-17475 Greifswald; ${ }^{3}$ Signature Diagnostics, \\ D-14469 Potsdam; ${ }^{4}$ Institute of Pathology, University Hospital Aachen, RWTH Aachen, D-52074 Aachen, Germany
}

Received March 31, 2009; Accepted July 20, 2009

DOI: $10.3892 / \mathrm{mmr} 00000207$

\begin{abstract}
The aim of the present study was to evaluate the expression of topoisomerase II $\alpha$ (TOP2A) and HER-2 in tumor epithelial and adjacent stromal cells in ovarian cancer (OvCa). Immunohistochemistry for TOP2A and HER-2 was performed on $50 \mathrm{OvCa}$ specimens from the Tumor Bank of Ovarian Cancer, and was correlated to established clinicopathological parameters. TOP2A was expressed in $98 \%$ and HER-2 in 52\% of the OvCa specimens. Moderate expression of TOP $2 \mathrm{~A}$ was detected in $72 \%$ of the adjacent stromal cells. TOP2A and HER-2 were strongly expressed in the tumor epithelial cells of primary $\mathrm{OvCa}$, but reduced in recurrent $\mathrm{OvCa}$. Stromal expression of TOP2A increased in recurrent OvCa after platinum-based chemotherapy. In conclusion, distinct epithelial and stromal cell expression of TOP2A and HER-2 is a novel feature in the tumor biology of OvCa. Differential cellular expression of TOP2A in relation to previous chemotherapy probably reflects a modified activity of the 'stromal compartment' in drug resistance. Thus, analysis of TOP2A expression in tumor and stromal OvCa cells can aid in iden-
\end{abstract}

Correspondence to: Dr Radoslav Chekerov, Department of Obstetrics and Gynecology, Campus Virchow Clinic, Charité University Hospital, Augustenburger Platz 1, D-13353 Berlin, Germany

E-mail: radoslav.chekerov@charite.de

${ }^{*}$ Contributed equally

Abbreviations: FIGO, Federation of Obstetrics and Gynecology; IRS, immunoreactive score, TOP2A, topoisomerase II $\alpha$, OvCa, ovarian cancer

Key words: topoisomerase II $\alpha$, HER-2/neu, ovarian cancer, immunohistochemistry tifying subgroups of patients who may have a more favorable response to chemotherapy.

\section{Introduction}

Ovarian cancer $(\mathrm{OvCa})$ has the highest mortality rate of all female gynaecological cancers, with an overall 5-year survival rate of approximately $30 \%(1,2)$. At the time of primary diagnosis, most patients have advanced stage disease (FIGO III/IV) $(3,4)$. Cytoreductive surgery is known to have a strong prognostic effect on survival (4-6). Despite the initial high response rates of current standard chemotherapy with carboplatin and paclitaxel, most patients relapse and soon succumb to the disease due to tumor progression (1). Unfortunately, the complex mechanisms of platinum resistance are still poorly understood (7). Thus, the confirmation of novel molecular factors is a promising strategy that may help to individualize chemotherapy for $\mathrm{OvCa}$.

Topoisomerase II $\alpha$ (TOP2A) is an important proliferation marker in solid cancer $(8,9)$, with significant expression during the $\mathrm{S}$ and $\mathrm{G} 2-\mathrm{M}$ phases $(9,10)$. TOP2A is also the cellular target of anticancer drugs such as etoposide and doxorubicin (11), and has been implicated in contributing to atypical multidrug resistance in OvCa $(12,13)$. Nonetheless, it does not appear to predict resistance as strongly as other factors. Only a few studies have evaluated TOP2A expression in OvCa cells, most describing increased amplification in advanced tumor stages associated with poor clinical outcome (8).

The HER-2 proto-oncogene is essential for tumor growth and proliferation, with a wide range of amplification in solid tumors (14-16). Different ligands can bind through its extracellular segments, and can mediate intracellular signal transduction through tyrosine kinase activity. HER-2 is also a target for novel therapeutic approaches, such as trastuzumab, a recombinant antibody designed to block signaling through the HER-2 receptor. HER2 expression in OvCa shows rates of $1.8-76 \%$, but data related to its prognostic value are controversial (16-18). 
The TOP2A gene is located adjacent to the HER-2 gene on chromosome 17q, and is either amplified or deleted in a great majority of HER-2-amplified primary tumors $(6,19)$. Recent trials suggest that amplification (and/or deletion) of TOP2A may lead to sensitivity or resistance to clinically used TOP2A inhibitors (14). Nevertheless, data regarding the expression of TOP2A and HER-2 in OvCa are limited.

The aim of this prospective study was to analyze the expression of TOP2A and HER-2/neu in malignant epithelial cells and adjacent stromal cells in primary and recurrent OvCa.

\section{Materials and methods}

Tissue specimens. OvCa samples were obtained intra-operatively from 50 patients ( 24 with primary and 26 with relapsed cancers) at the Department of Gynecology, Charité University of Berlin, Germany. Specimens were collected and documented according to the surgical and pathological standard operating procedures of the Tumor Bank Ovarian Cancer using a systematic intraoperative documentation tool (3). The control group included 4 cystadenomas and 7 normal ovaries from 11 women who underwent surgery for benign disease (4 cystadenomas, 3 leiomyomas and 4 benign ovarian cysts). After excision, the tissues were transferred to $4 \%$ formalin and paraffin embedded. All samples underwent standard histological examination by an experienced pathologist (I.K.). The Ethics Committee of the Charité University Hospital approved the study protocol. Pre-operative informed consent was obtained from each patient.

Immunohistochemistry. Immunohistochemistry was performed on paraffin sections using the standard avidin-biotin complex method. Endogenous peroxidase activity was quenched with a hydrogen peroxide solution. Non-specific binding sites were blocked with CAS solution (Zymed Laboratories, CA). Primary antibodies included Ki-S1 for TOP2A (IgG2a, 1:80) and A0485 for HER-2 (IgG1, 1:200) (Dako Cytomation, Glostrup, Denmark). Biotinylated secondary antibody, the tertiary avidin-biotin complex complex and the AEC Substrate Kit from Biocarta (Hamburg, Germany) were used for detection. For each sample, a negative control was performed. All histological features were evaluated separately by two investigators (R.C. and I.K.).

For the evaluation of TOP2A, the semiquantitative immunoreactive score (IRS) was applied. In each case, a minimum of 1000 cells were counted in five to ten high-power fields (x400) to determine dye intensity and the percentage of positive cells. Mean dye intensity was assessed as follows: 0 , negative; 1 , low; 2, moderate; and 3, strong intensity. The percentages of stained cells were classified as follows: $0 \%$, negative; $1,<0 \%$; $2,10-50 \% ; 3,51-80 \%$; and $4,>80 \%$ positively stained cells. An IRS score of $0-2$ was considered negative, whereas moderate (IRS 3-6), or strong (IRS 7-12) immunostaining indicated TOP2A overexpression.

HER-2 immunostaining was evaluated following the Dako HercepTest ${ }^{\mathrm{TM}}$ protocol: score 0, no staining or membrane staining of $<10 \%$ of the cells; score $1+$, partial staining in $>10 \%$ of the cells; score $2+$, moderate or $3+$, strong membrane staining in $>10 \%$ of the cells. A score of 0 and 1+ was considered negative, and a score of $2+$ and $3+$, positive.
Table I. Clinicopathological characteristics of the patients.

\begin{tabular}{lrrr}
\hline Parameter & $\begin{array}{c}\text { Primary } \\
\text { cancer }\end{array}$ & $\begin{array}{c}\text { Recurrent } \\
\text { cancer }\end{array}$ \\
\hline Ovarian cancer samples & $24(48.0 \%)$ & $26(52.0 \%)$ \\
Histology & & & \\
Serous-papillary & $14(58.3 \%)$ & $23(88.5 \%)$ \\
Endometrioid & $5(20.8 \%)$ & 2 & $(7.7 \%)$ \\
Mucinous & $2(8.4 \%)$ & 1 & $(3.8 \%)$ \\
Serous-mucinous & $3(12.5 \%)$ & 0 & \\
FIGO stage & & & \\
I & $5(20.8 \%)$ & 2 & $(7.7 \%)$ \\
II & $1(4.2 \%)$ & 0 & \\
III & $8(33.3 \%)$ & $18(69.2 \%)$ \\
IV & $10(41.7 \%)$ & $6(23.1 \%)$
\end{tabular}

Histological grade

$\begin{array}{lrr}\text { I } & 2(8.3 \%) & 6(23.1 \%) \\ \text { II } & 10(41.7 \%) & 8(30.8 \%) \\ \text { III } & 12(50.0 \%) & 12(46.1 \%)\end{array}$

Ascites

$\leq 500 \mathrm{ml} \quad 13(54.2 \%) \quad 21(80.8 \%)$

$>500 \mathrm{ml} \quad 11(45.8 \%) \quad 5(19.2 \%)$

Postoperative residual tumor mass

Macroscopically tumor-free $\quad 15(62.5 \%) \quad 9(34.6 \%)$

Tumor residuals $\quad 9(37.5 \%) \quad 17(65.4 \%)$

FIGO, Federation of Obstetrics and Gynecology.

Statistical analysis. For statistical analysis, the $\chi^{2}$ test was used to compare immunostaining with clinicopathological characteristics. Evaluations were performed using SPSS 15.0 statistical software (SPSS Inc., Chicago, IL). For survival analysis, KaplanMeier analysis and Cox regression were applied. A p-value $<0.05$ was considered to indicate statistical significance.

\section{Results}

Patient and tumor characteristics. The mean age of the patients was 54.0 years (range 26-86). Most patients presented advanced FIGO stage III $(n=26)$ and IV $(n=16)$ disease, with predominantly serous histology $(n=37)$. At the time of surgery, $\leq 500 \mathrm{ml}$ malignant ascites were found in 34 patients, while 16 patients had $>500 \mathrm{ml}$ ascites. In 24 women, complete tumor resection (macroscopically tumor-free) was achieved. The main clinicopathological characteristics of the patients are summarized in Table I.

Twenty-four of the 50 women with primary disease had never been treated with chemotherapy prior to surgery (platinum naïve), whereas 26 with recurrent OvCa had been previously treated with platinum-based chemotherapy (platinum/paclitaxel, $\mathrm{n}=24$; platinum/cyclophosphamide, $\mathrm{n}=2$ ). Thirteen women underwent surgery after the first relapse, 10 after the second and 3 after the third. 


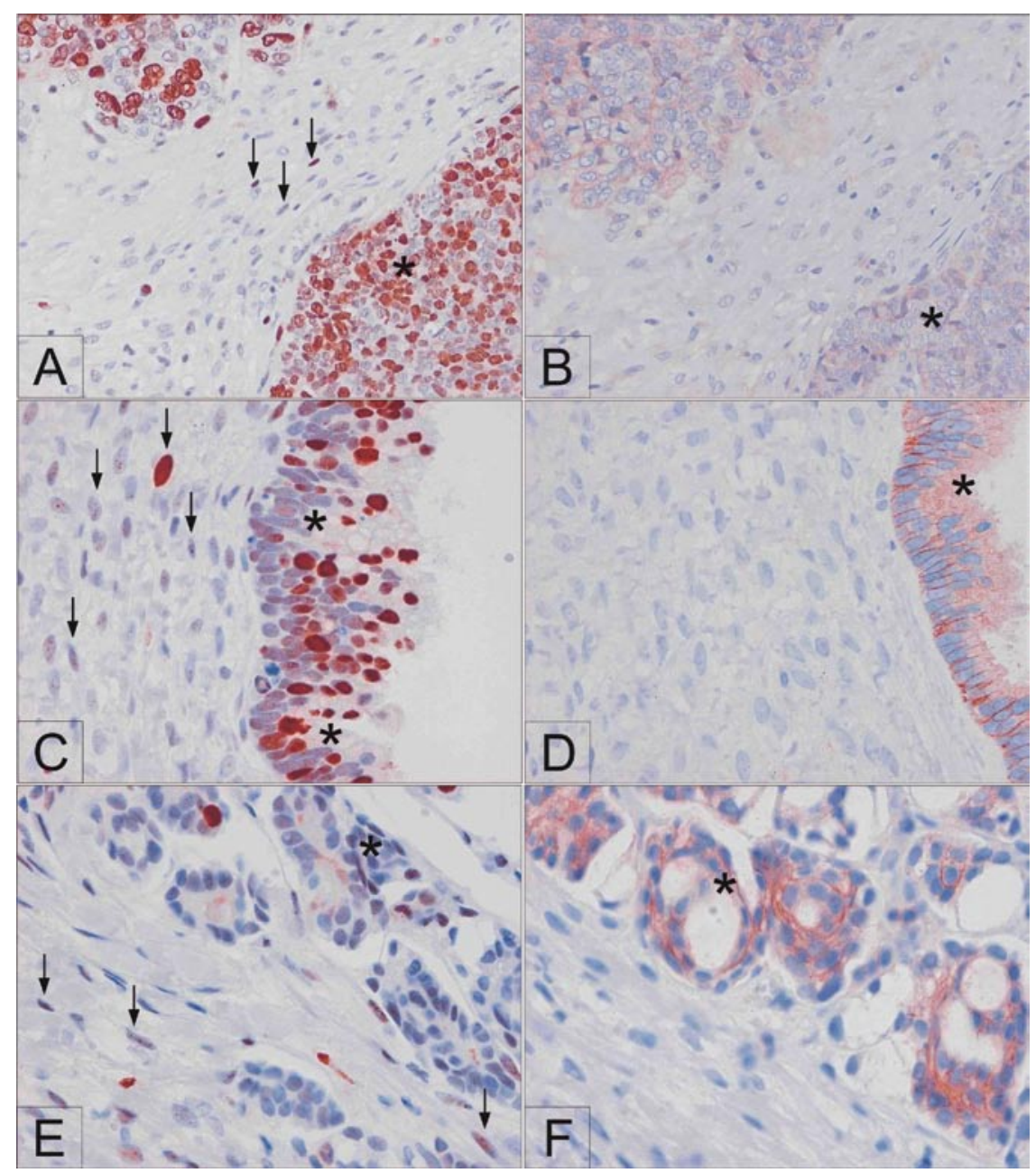

Figure 1. Immunohistochemical labeling of TOP2A protein expression (A, C and E) and HER-2 activity (B, D and F) in primary endometrioid ovarian cancer (A and B) (x200), primary mucinous ovarian cancer (C and D) (x400) and recurrent serous ovarian cancer (E and F) (x400). Expression of TOP2A is nuclear, and that of HER-2 is on the membrane of tumor cells (asterisks). Significant immunostaining in the adjacent stromal cells evaluated for TOP2A is barely detectable (arrows). HER-2 exhibits no activity in stromal fibroblasts (B, D and F).

Immunohistochemistry. Positive TOP2A immunostaining (IRS $\geq 3$ ) was observed in tumor cells (primary and recurrent) in 49 of the 50 patients; $66 \%$ ( $n=33$ ) were strongly and $32 \%$ $(\mathrm{n}=16)$ were moderately positive (Figs. 1 and 2 ). In adjacent stromal cells of primary and recurrent OvCa, TOP2A expression was observed to be strong in $12 \%(\mathrm{n}=6)$, moderate in $60 \%$ $(n=30)$ and negative in $28 \%(n=14)$ of the specimens (Fig. 2). Antibody staining was usually nuclear. Thus, in only one patient with serous recurrent $\mathrm{OvCa}$ were both epithelium and stromal cells negative for TOP2A.

Expression of HER-2 was detected in the tumor epithelium of primary and recurrent $\mathrm{OvCa}$ as membrane staining. A strong positive score (3+) was determined in 9 patients $(18 \%)$ and a moderate positive score (2+) in 17 patients (34\%) (Fig. 2). Negative HER-2 immunostaining (0 or 1+) was observed in 24 patients (48\%). No HER-2 membrane staining was observed in the stromal cells of any of the $50 \mathrm{OvCa}$ samples.

Normal ovarian tissues had negative $(85.7 \%)$ or low $(14.3 \%)$ expression of TOP2A in the epithelial cells, and all adjacent stromal cells were negative (Table II). TOP2A expression was slightly stronger in the epithelial cells of cystadenomas: $25 \%$ had strong, 50\% moderate and $25 \%$ negative expression, while most stromal cells $(75 \%)$ were negative.
In all 50 adenocarcinomas, TOP2A was significantly overexpressed in $98 \%$ of the tumor epithelial cells (median IRS=9, range 2-12) $(\mathrm{p}<0.01)$ and moderately expressed in $72 \%$ of the adjacent stroma (median IRS $=4$, range $0-12)(\mathrm{p}<0.05)$ (Fig. 2). HER-2 expression was also stronger in the tumor epithelium compared to weak activity in cystadenomas and negative expression in normal epithelial cells $(\mathrm{p}<0.05)$. In $52 \%$ of the tumor cells, the median positive HER-2 score was $2+$ (range $0-3+$ ), whereas $48 \%$ of the cells were negative (Fig. 2). Tumor epithelium expressed TOP2A more strongly than it did HER-2 (98 vs. $52 \%$, p<0.05, Fig. 2).

The expression of TOP2A and HER-2 in the tumor epithelial and adjacent stromal cells was further analyzed according to pre-treatment status (Table II). Tumor cells of primary OvCa exhibited mostly moderate $(25 \%)$ or strong $(75 \%)$ positive expression of TOP2A. In the epithelial cells of primary $\mathrm{OvCa}$, weak to strong membrane expression of HER-2 was detected, with a score of $2+(41.7 \%)$ or $3+(20.8 \%)$, whereas $37.5 \%$ of cells were negative (Table II; Fig. 1). Moreover, in primary cancers, a significant number of adjacent stromal cells (50\%) clearly demonstrated moderate expression, while in several specimens (12.5\%) strong TOP2A expression was also observed in the nuclei (Table II; Fig. 1A and C). Negative stromal TOP2A 


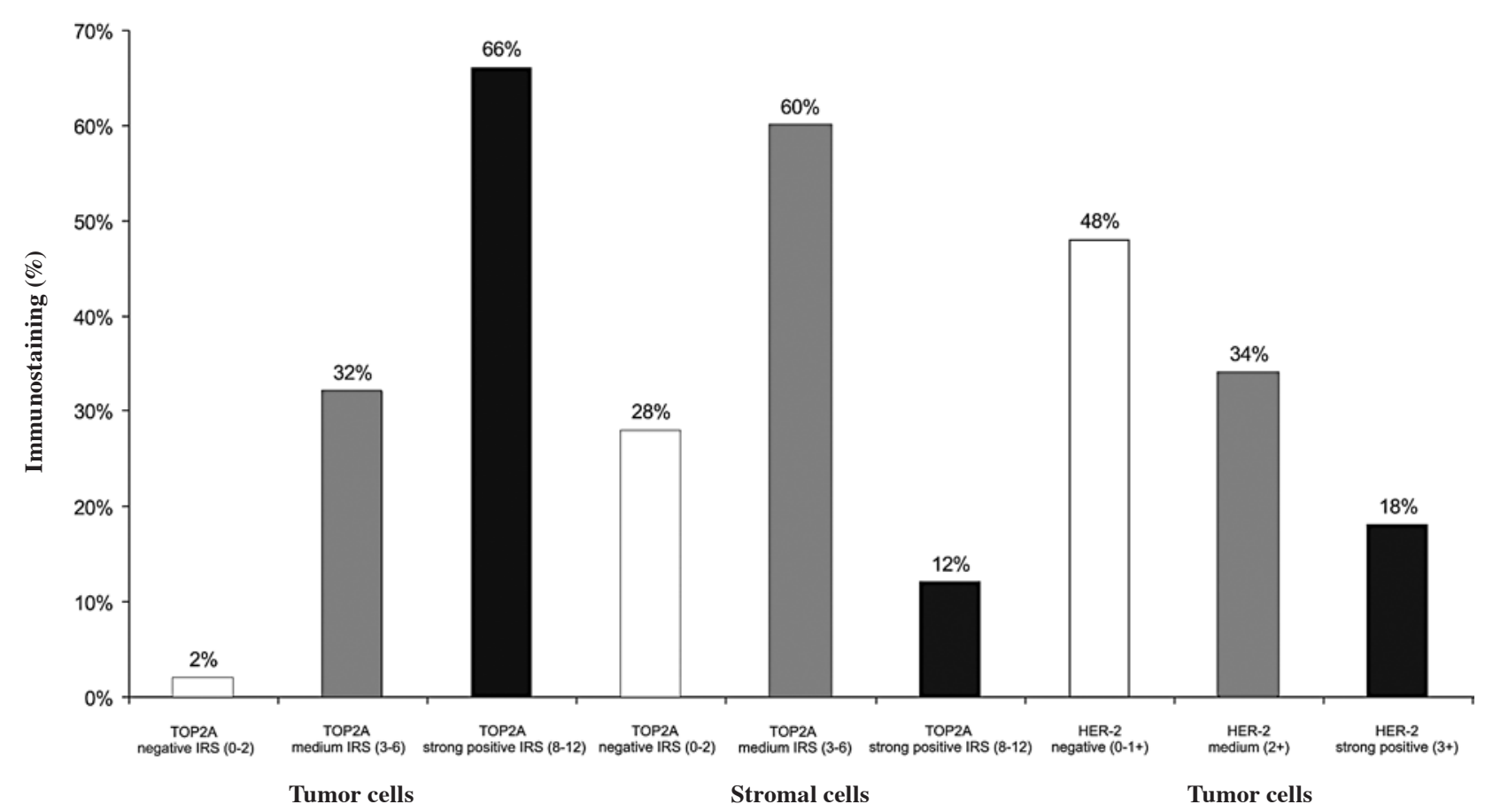

Figure 2. Distinct expression of TOP2A and HER-2 in tumor epithelium and stromal cells. TOP2A was negative (IRS score $0-2$ ) in $2 \%$ of the tumor cells and $28 \%$ of the adjacent stromal cells, while HER-2 was negative (0-1+) in $48 \%$ of the tumor cells (white bars). TOP2A was moderately expressed (IRS score 3-6) in $32 \%$ of the tumor cells and $60 \%$ of the stromal cells, while HER-2 was moderately expressed in $34 \%$ of the tumor cells (grey bars). TOP2A was strongly expressed (IRS score 8-12) in 66\% of the tumor cells and only $12 \%$ of the adjacent stromal cells, while HER-2 was strongly expressed (3+) in $18 \%$ of the tumor cells (black bars).

Table II. Tumor and stromal cell expression of TOP2A and HER-2 and correlation with chemotherapy status (platinum pretreatment).

\begin{tabular}{|c|c|c|c|c|c|c|}
\hline \multirow[b]{2}{*}{ Target } & \multirow[b]{2}{*}{ Cell type } & \multirow[b]{2}{*}{ Tissue } & \multicolumn{3}{|c|}{ Expression } & \multirow[b]{2}{*}{ p-value } \\
\hline & & & Negative & Moderate & Strong & \\
\hline \multirow{8}{*}{$\begin{array}{l}\text { TOP2A } \\
\text { (IRS score) }\end{array}$} & \multirow[t]{4}{*}{ Epithelium } & Normal ovary & $6(85.7 \%)$ & $1(14.3 \%)$ & 0 & \multirow[t]{4}{*}{$\mathrm{p}<0.01$} \\
\hline & & Benign cystadenoma & $1(25.0 \%)$ & $2(50.0 \%)$ & $1(25.0 \%)$ & \\
\hline & & Primary cancer (platinum naïve) & 0 & $6(25.0 \%)$ & $18(75.0 \%)$ & \\
\hline & & Recurrent cancer (platinum pre-treated) & $1(3.8 \%)$ & $10(38.5 \%)$ & $15(57.7 \%)$ & \\
\hline & \multirow{4}{*}{ Stroma } & Normal ovary & $7(100.0 \%)$ & 0 & 0 & \multirow[t]{4}{*}{$\mathrm{p}<0.05$} \\
\hline & & Benign cystadenoma & $3(75.0 \%)$ & $1(25.0 \%)$ & 0 & \\
\hline & & Primary cancer (platinum naïve) & $9(37.5 \%)$ & $12(50.0 \%)$ & $3(12.5 \%)$ & \\
\hline & & Recurrent cancer (platinum pre-treated) & $5(19.2 \%)$ & $18(69.2 \%)$ & $3(11.6 \%)$ & \\
\hline \multirow{4}{*}{$\begin{array}{l}\text { HER-2 } \\
\text { (Hercep score) }\end{array}$} & \multirow[t]{4}{*}{ Epithelium } & Normal ovary & $7(100.0 \%)$ & 0 & 0 & \multirow[t]{4}{*}{$\mathrm{p}<0.05$} \\
\hline & & Benign cystadenoma & $4(100.0 \%)$ & 0 & 0 & \\
\hline & & Primary cancer (platinum naïve) & $9(37.5 \%)$ & $10(41.7 \%)$ & $5(20.8 \%)$ & \\
\hline & & Recurrent cancer (platinum pre-treated) & $15(57.7 \%)$ & $7(26.9 \%)$ & $4(15.4 \%)$ & \\
\hline
\end{tabular}

IRS score: 0-2, negative; 3-6, moderate; 8-12, strong expression. Hercep test score: 0-1+, negative; $2+$, moderate; $3+$, strong expression.

immunostaining was observed in one-third of these cases (37.5\%). In women with recurrent OvCa, tumor epithelial cells presented moderate $(38.5 \%)$ to strong $(57.7 \%)$ expression of TOP $2 \mathrm{~A}$, whereas $3.8 \%$ of cells were negative. In this group, the tumor cells were predominantly HER-2 negative (57.7\%), while $26.9 \%$ had moderate and $15.4 \%$ strong expression (Table II;
Fig. 1). Thus, in recurrent OvCa, immunostaining showed a significant decrease in overall TOP2A and HER-2 expression in the tumor cells $(\mathrm{p}<0.01$ and $<0.05$, respectively). Notably, TOP2A expression in the stromal cells of recurrent OvCa increased, with $19.2 \%$ showing negative, $69.2 \%$ moderate and $11.6 \%$ strong immunostaining $(\mathrm{p}<0.05)$ (Table II; Fig. 1E). 
Table III. Correlation between simultaneous TOP2A and HER-2 expression in tumor and stromal cells. ${ }^{a}$

TOP2A and HER-2/neu expression

\begin{tabular}{|c|c|c|c|c|}
\hline $\begin{array}{l}\text { Chemotherapy status } \\
\text { (platinum pre-treatment) }\end{array}$ & $\begin{array}{c}\text { TOP2A } \\
\text { epithelial cells }\end{array}$ & $\begin{array}{c}\text { TOP2A } \\
\text { stromal cells }\end{array}$ & $\begin{array}{l}\text { HER-2 } \\
\text { epithelial cells }\end{array}$ & Percentage \\
\hline \multirow{5}{*}{$\begin{array}{l}\text { Primary cancer } \\
\text { (platinum naïve) }\end{array}$} & + & + & + & $8(33.3 \%)$ \\
\hline & + & - & + & $7(29.2 \%)$ \\
\hline & + & + & - & $5(20.8 \%)$ \\
\hline & + & - & - & $4(16.7 \%)$ \\
\hline & - & - & - & 0 \\
\hline \multirow{5}{*}{$\begin{array}{l}\text { Recurrent cancer } \\
\text { (platinum pre-treated) }\end{array}$} & + & + & + & $10(38.5 \%)$ \\
\hline & + & - & + & $1(3.8 \%)$ \\
\hline & + & + & - & $11(42.3 \%)$ \\
\hline & + & - & - & $3(11.6 \%)$ \\
\hline & - & - & - & $1(3.8 \%)$ \\
\hline
\end{tabular}

aTumor cells presenting expression of both targets in 15 samples $(62.5 \%)$ of primary and 21 samples $(42.3 \%)$ of relapsed ovarian cancers $(\mathrm{p}<0.05)$. Simultaneous tumor and stromal TOP2A expression was observed in $54.1 \%$ of primary cancers compared to $80.8 \%$ of recurrent disease. $+/$-, positive IRS score $(\geq 3)$ /negative IRS score (0-2). +/-, positive Hercep score $(\geq 2+)$ /negative Hercep score $(0-1)$.

Correlation between TOP $2 A$ and HER-2 expression. A direct correlation was observed between HER-2 and TOP2A immunostaining in all tumor epithelial cells $(\mathrm{p}<0.05)$; TOP2A had a median IRS of 9 (range 2-12) and HER-2 a median score of $2+$ (range $0-3+$ ).

Primary OvCa had simultaneous TOP2A and HER-2 expression in $62.5 \%$ of the tumor cells. Eight samples (33.3\%) also showed simultaneous TOP2A stromal activity (Table III). In 14 of 24 primary OvCa patients $(54.1 \%)$, positive TOP2A activity was observed in both the tumor and stromal cells. In recurrent $\mathrm{OvCa}$, only $42.3 \%$ of the patients presented simultaneous TOP2A and HER-2 activity in the tumor epithelial cells, while $38.5 \%$ showed additional TOP2A stromal activity. Increased simultaneous TOP2A tumor and stromal cell expression was detected in 21 of the 26 recurrent patients (80.8\%). Only one recurrent adenocarcinoma was negative for both targets in tumor and stromal cells.

Correlation between classical clinical parameters and survival analysis. After a median follow-up of 22 months (0-74 months), 18 patients $(36 \%)$ (11 with primary and 7 with recurrent cancer) remained alive. Thirty-two patients (64\%) (13 with primary, 19 with relapsed cancer) succumbed to the disease due to tumorspecific causes during the observation period.

In the survival analysis, patients with primary disease who underwent optimal tumor resection (14 tumor-free patients vs. 11 patients with residual tumor, $\mathrm{p}=0.002$ ) or who presented initially low amounts of ascites ( 13 cases $\leq 500 \mathrm{ml}$ vs. 11 cases $>500 \mathrm{ml}$ ascites, $\mathrm{p}=0.002$ ) achieved an improved overall survival. For patients with recurrent disease (13 with first, 10 with second and 3 with third relapse), no survival benefit was ascertained according to the tumor residual mass ( 8 tumorfree patients vs. 16 patients with residual tumor, n.s.) or ascite volume (19 cases $\leq 500 \mathrm{ml}$ vs. 5 cases $>500 \mathrm{ml}$ ascites, n.s.). TOP2A tumor and stromal expression had no influence on overall survival.

\section{Discussion}

In this prospective study, we identified a distinct cellular expression for TOP2A and HER-2 in 50 primary and recurrent ovarian adenocarcinomas. Our results are in agreement with previous immunohistochemical studies, which found that TOP2A $(8,20)$ and HER-2 $(16,21)$ presented increased activity in OvCa compared to benign and normal ovaries. Notably, we evaluated specific activity for TOP $2 \mathrm{~A}$ in both the tumor epithelium as well as in stromal cells in the majority of the analyzed samples. TOP2A immunostaining was much more abundant in the tumor epithelium than in the adjacent stroma $(9,22)$. TOP2A amplification was correlated with HER-2 activity in the tumor epithelial cells. It is known that TOP2A appears to be a sensitive marker in $\mathrm{OvCa}$, and its activity is commonly associated with HER2 expression $(13,14,23)$.

Although the complex heterogeneity of OvCa tissue is well known, no studies have separately confirmed target expression in the tumor epithelium and adjacent stromal cells. Moreover, most studies have evaluated only the tumor compartment, whereas data regarding target expression in the stromal cells of OvCa are limited (22). Our results demonstrate clear expression of TOP2A at the protein level in both cell types.

The development of platinum resistance is a major clinical problem encountered in OvCa chemotherapy $(7,12)$. A number of studies discuss the potential role of TOP2A as a predictor of response to chemotherapy $(13,14,20,24,25)$. Although limited to a small patient group, we found stronger expression of TOP2A and HER-2 in the tumor cells of chemotherapy-naïve patients than in patients previously treated with platinum. Interestingly, inverse patterns were found in the adjacent stromal cells of a few patients; TOP2A expression in relapsed samples after platinum pre-treatment was higher than TOP2A expression in the stroma of primary disease patients. These results indicate for the first time the complex aspects of TOP2A expression in epithelial and stromal OvCa cells with respect to previous 
treatment. Additional multicenter trials with a large number of patients are needed to support these findings.

Tumor invasion is thought to be highly dependent on dynamic interactions with the surrounding extracellular matrix and neighboring cells (26-28). Stromal changes and tissue remodeling are well-known factors that induce the invasion of epithelial cancers $(22,27)$. Here, stromal fibroblasts play a crucial role $(29,30,31)$. In this context, the expression of TOP2A in adjacent stromal cells after platinum-based chemotherapy might also reflect some anatomic features of the excised tissue site (i.e., native stroma to the anatomic location). Evidence suggests that invasive epithelial tumor cells can activate so-called 'carcinoma-associated fibroblasts' as part of the desmoplastic reaction, which in turn can promote the growth and invasion of tumor cells (32-35). In OvCa, stromal activation has been implicated in a hypothesis supporting an OvCa-prone preneoplastic phenotype (36).

The stratification of subgroups of patients who may benefit from specific targeted therapies is a powerful clinical strategy $(6,37)$. At present, approved agents such as topotecan and doxorubicine constitute an important element of therapy for recurrent OvCa $(11,14,38)$. Nevertheless, only a few patients achieve long-term stabilization, and most responses are temporary. Although our understanding of tumor biology is expanding, the clinical benefits achieved have been disappointing, and there are no available tumor-associated factors that can predict the cohort of patients who may benefit from specific therapy regimes in this patient setting $(18,24)$. In this context, the analysis of target expression in adjacent stromal cells of relapsed OvCa adds to our understanding of drug resistance and warrants further study in a multicenter setting.

\section{References}

1. Pfisterer $\mathrm{J}$ and du Bois A: Das Ovarialkarzinom: therapeutische standards - Klinische Empfehlungen. Stuttgart, Georg Thieme Verlag, 2001.

2. Ferlay J, Autier P, Boniol M, et al: Estimates of the cancer incidence and mortality in Europe in 2006. Ann Oncol 18: 581-592, 2007.

3. Sehouli J, Koensgen D, Mustea A, et al: 'IMO' - intraoperative mapping of ovarian cancer. Zentralbl Gynakol 125: 129-135, 2003.

4. Heintz AP, Odicino F, Maisonneuve P, et al: Carcinoma of the ovary. FIGO 6th Annual Report on the Results of Treatment in Gynecological Cancer. Int J Gynaecol Obstet 95 (Suppl 1): 161-192, 2006.

5. Bristow RE, Tomacruz RS, Armstrong DK, Trimble EL and Montz FJ: Survival effect of maximal cytoreductive surgery for advanced ovarian carcinoma during the platinum era: a metaanalysis. J Clin Oncol 20: 1248-1259, 2002.

6. Schindlbeck C, Hantschmann P, Zerzer M, et al: Prognostic impact of KI67, p53, human epithelial growth factor receptor 2, topoisomerase IIalpha, epidermal growth factor receptor, and $\mathrm{nm} 23$ expression of ovarian carcinomas and disseminated tumor cells in the bone marrow. Int J Gynecol Cancer 17: 1047-1055, 2007.

7. Helleman J, Jansen MP, Span PN, et al: Molecular profiling of platinum resistant ovarian cancer. Int J Cancer 118: 1963-1971, 2006.

8. Gotlieb WH, Goldberg I, Weisz B, Davidson B, Novikov I, Kopolovic J and Ben-Baruch G: Topoisomerase II immunostaining as a prognostic marker for survival in ovarian cancer. Gynecol Oncol 82: 99-104, 2001.

9. Heck MM and Earnshaw WC: Topoisomerase II: A specific marker for cell proliferation. J Cell Biol 103: 2569-2581, 1986

10. Wang J: Cellular roles of DNA topoisomerases: a molecular perspective. Nat Rev Mol Cell Biol 3: 430-440, 2002.

11. Burden DA and Osheroff N: Mechanism of action of eukaryotic topoisomerase II and drugs targeted to the enzyme. Biochim Biophys Acta 1400: 139-154, 1998.
12. Larsen AK and Skladanowski A: Cellular resistance to topoisomerase-targeted drugs: from drug uptake to cell death. Biochim Biophys Acta 1400: 257-274, 1998.

13. Hengstler JG, Lange J, Kett A, et al: Contribution of c-erbB-2 and topoisomerase IIalpha to chemoresistance in ovarian cancer. Cancer Res 59: 3206-3214, 1999.

14. Jarvinen TA and Liu ET: Simultaneous amplification of HER-2 (ERBB2) and topoisomerase IIalpha (TOP2A) genes - molecular basis for combination chemotherapy in cancer. Curr Cancer Drug Targets 6: 579-602, 2006.

15. Slamon DJ, Godolphin W, Jones LA, et al: Studies of the HER-2/ neu proto-oncogene in human breast and ovarian cancer. Science 244: 707-712, 1989.

16. Meden $\mathrm{H}$ and Kuhn W: Overexpression of the oncogene c-erbB-2 (HER2/neu) in ovarian cancer: a new prognostic factor. Eur J Obstet Gynecol Reprod Biol 71: 173-179, 1997.

17. Serrano-Olvera A, Duenas-Gonzalez A, Gallardo-Rincon D, Candelaria $\mathrm{M}$ and De la Garza-Salazar J: Prognostic, predictive and therapeutic implications of HER2 in invasive epithelial ovarian cancer. Cancer Treat Rev 32: 180-190, 2006.

18. Tuefferd M, Couturier J, Penault-Llorca F, et al: HER2 status in ovarian carcinomas: A multicenter GINECO study of 320 patients. PLoS ONE 2: e1138, 2007.

19. Simon R, Atefy R, Wagner U, et al: HER-2 and TOP2A gene amplification in urinary bladder cancer. Verh Dtsch Ges Pathol 86: 176-183, 2002.

20. Cornarotti M, Capranico G, Bohm S, et al: Gene expression of DNA topoisomerases I, II alpha and II beta and response to cisplatin-based chemotherapy in advanced ovarian carcinoma. Int J Cancer 67: 479-484, 1996.

21. Mano MS, Awada A, Di Leo A, et al: Rates of topoisomerase II-alpha and HER-2 gene amplification and expression in epithelial ovarian carcinoma. Gynecol Oncol 92: 887-895, 2004.

22. Tlsty TD and Hein PW. Know thy neighbor: stromal cells can contribute oncogenic signals. Curr Opin Genet Dev 11: 54-59, 2001.

23. Tanner B, Pilch H, Schäffer U, et al: Expression of c-erbB-2 and topoisomerase II alpha in relation to chemoresistance in ovarian cancer. Zentralbl Gynakol 124: 176-183, 2002.

24. Pritchard KI: HER-2 and topoisomerase II as predictors of response to chemotherapy. J Clin Oncol 26: 736-744, 2008.

25. Simon R, Atefy R, Wagner U, et al: HER-2 and TOP2A coamplification in urinary bladder cancer. Int J Cancer 107: 764-772, 2003.

26. Park CC, Bissell MJ and Barcellos-Hoff MH: The influence of the microenvironment on the malignant phenotype. Mol Med Today 6: 324-329, 2000.

27. Krtolica A and Campisi J: Cancer and aging: a model for the cancer promoting effects of the aging stroma. Int J Biochem Cell Biol 34: 1401-1414, 2002.

28. DePinho RA: The age of cancer. Nature 408: 248-254, 2000.

29. Tlsty TD: Stromal cells can contribute oncogenic signals. Semin Cancer Biol 11: 97-104, 2001.

30. Chrenek MA, Wong P and Weaver VM: Tumor-stromal interactions. Integrins and cell adhesions as modulators of mammary cell survival and transformation. Breast Cancer Res 3: 224-229, 2001.

31. Olumi AF, Grossfeld GD, Hayward SW, Carroll PR, Tlsty TD and Cunha GR: Carcinoma-associated fibroblasts direct tumor progression of initiated human prostatic epithelium. Cancer Res 59: 5002-5011, 1999

32. Tuxhorn JA, Ayala GE, Smith MJ, Smith VC, Dang TD and Rowley DR: Reactive stroma in human prostate cancer: induction of myofibroblast phenotype and extracellular matrix remodeling. Clin Cancer Res 8: 2912-2923, 2002.

33. Skobe M and Fusenig NE: Tumorigenic conversion of immortal human keratinocytes through stromal cell activation. Proc Natl Acad Sci USA 95: 1050-1055, 1998.

34. Sternlicht MD, Lochter MD, Sympson CJ, et al: The stromal proteinase MMP3/stromelysin-1 promotes mammary carcinogenesis. Cell 98: 137-146, 1999.

35. Barcellos-Hoff MH and Ravani SA: Irradiated mammary gland stroma promotes the expression of tumorigenic potential by unirradiated epithelial cells. Cancer Res 60: 1254-1260, 2000.

36. Bingham C, Roberts D and Hamilton TC: The role of molecular biology in understanding ovarian cancer initiation and progression. Int J Gynecol Cancer 11: 7-11, 2001.

37. See HT and Kavanagh JJ: Novel agents in epithelial ovarian cancer. Cancer Invest 22: 29-44, 2004.

38. Kaufmann SH: Cell death induced by topoisomerase-targeted drugs: more questions than answers. Biochim Biophys Acta 1400: 195-211, 1998. 